\title{
Cartographic product as a service for easier access to INSPIRE data
}

\author{
Andrius Balčiūnas ${ }^{\mathrm{a}}{ }^{*}$, Giedrè Beconytė, ${ }^{\mathrm{a}}$ and Juliana Karčiauskienė ${ }^{\mathrm{b}}$ \\ ${ }^{a}$ Vilnius University, andrius.balciunas@chgf.vu.lt, giedre.beconyte@gf.vu.lt \\ ${ }^{b}$ SE GIS-Centras, j.karciauskiene@gis-centras.lt \\ * Corresponding author
}

Keywords: spatial data, infrastructure, map service, INSPIRE, WMS, web mapping, cascading WMS

\begin{abstract}
:
Since entering into force in May 2007, the Directive 2007/2/EC of the European Parliament and of the Council establishing Infrastructure for Spatial Information in Europe (INSPIRE directive) has been playing very important role in building spatial information infrastructures - both pan-European and at national level. The INSPIRE directive addresses 34 spatial data themes that open possibilities for a great variety of applications in the environmental domain. Technical specifications and guidelines describe the key components of data content and of implementation of web services. The roadmap of directive implementation has reached the last milestone in 21/10/2020 - all spatial data sets had to be provided to the INSPIRE geoportal ((https://inspire-geoportal.ec.europa.eu/) by all member states of the European Union.
\end{abstract}

Now, INSPIRE geoportal provides access to thousands of spatial data sets and services. View service is one of the most valuable data access type for the end users or client applications. According to the INSPIRE technical specifications, view services must be implemented using OGC standard of WMS or WMTS. View services can be used directly in the map viewer of the INSPIRE geoportal or in desktop GIS and various custom WEB applications. All this sounds fantastic but what's next? Is these thousands of diverse services the final result? Has the aim of INSPIRE directive been accomplished? Certainly not. Rich spatial data content is still scattered across INSPIRE themes and countries. The user has to find his own ways of using this content, how to combine fragments of data provided by different services into a consistent and valuable product.

Implementation of ISNPIRE directive has come into a new phase - application of the results in practice. In this article we share an idea of a cartographic product as a service that could play the key role in employing the INSPIRE spatial data content for real-life use cases.

Cartographic product as a service (CPAAS) is an early stage technical implementation of a cascading web map service. The main idea is combining of different WMS services provided for different themes by different countries into seamless thematic maps, for example: land management map, infrastructure map, forest protection map. Technical implementation of the service (Figure 1) allows connecting different WMS services provided by the member states into one single WMS service. Then, a uniform visualization style could be applied for the combined dataset. As the outcome, a WMS service could be provided, as a mashup of multiple WMS services, in a form of a consistent and comprehensive thematic map.

There are several benefits of suggested technical approach of CPAAS.

- A single WMS and seamless data coverage for the end user application. The user will be able to access thematic map instead of a bunch of services that may have different structure and style.

- Unified style. As set by the INSIPRE specifications, WMS services of individual countries contain a style parameter (a link to the SLD file) for each thematic map layer. Thus, uniform styling rules can be applied to all data provided as WMS.

- Dynamics. Requests to the CPASS will be dynamically forwarded to the specific WMS that comprise the CPAAS and the responses will be collected into the final image that can be use by the end user.

- Direct access of the data. The feature of WMS is that each request collects the data in the specified bounding box directly from the data source. Cascading WMS will collect data in the same way, just the requests will be forwarded to the component WMS simultaneously.

- Low infrastructure costs. Proposed solution is based on dynamic requests and relies on accessibility and capacity of the component WMS provided by the member states. INSPIRE has set very high requirements for WMS 
performance. Member states are obliged to comply with these requirements. Thus good overall performance of CPAAS can be expected.

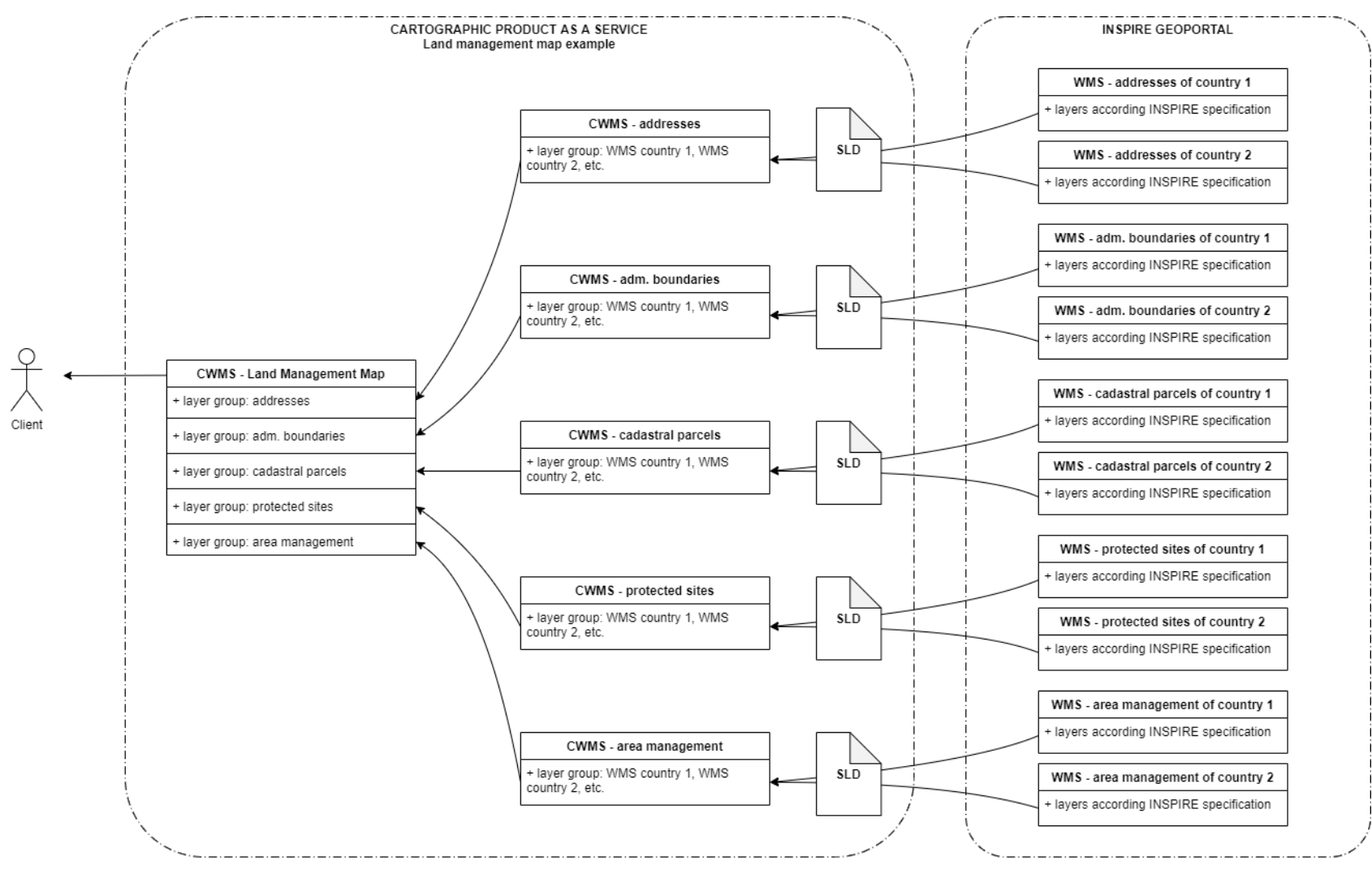

CWMS - Cascading Web Map Service, WMS - Web Map Service, SLD - Styled Layer Description

Figure 1. Implementation of cartographic product as a service based on cascading web map service

Currently, we are in the stage of technical implementation of CPAAS and introduce a proof of the concept. We present a working example of CPAAS for Land Management Map that combines original INSPIRE WMS services from at least 3 neighbour countries. By the end of 2021, we expect to have prepared fully effective implementation of CPAAS. 